\section{Autologous Hematopoietic Stem Cell Transplant for Systemic Sclerosis Improves Anemia from Gastric Antral Vascular Ectasia}

To the Editor:

Systemic sclerosis (SSc) is a severe autoimmune condition characterized by both fibrotic and vascular complications. This can progress to functionally devastating subcutaneous fibrosis, as well as death from pulmonary, cardiac, renal, or gastrointestinal (GI) involvement ${ }^{1}$. High-dose chemotherapy followed by autologous hematopoietic stem cell transplantation (HSCT) is the first therapy to show evidence of clinically significant improvement in skin and lung function as well as quality of life in SSc when compared to intravenous cyclophosphamide $(\mathrm{CYC})^{2}$. The multicenter, phase III randomized trial, Autologous Stem Cell Transplantation International Scleroderma, also showed a significant benefit in longterm, event-free survival with autologous HSCT compared to CYC, despite a higher early treatment-related mortality ${ }^{3}$. A publication from the European Group for Blood and Marrow transplantation (EBMT) has updated guidelines for autologous HSCT in autoimmune diseases, including SSc${ }^{4}$.

GI involvement is the presenting feature of the disease in $10 \%$ of patients with $\mathrm{SSc}^{5}$. A recent case-control study of unselected patients with SSc, without routine endoscopy, showed a $1 \%$ prevalence of gastric antral vascular ectasia (GAVE) in $\mathrm{SSc}^{6}$. This study also highlighted the significant morbidity of GAVE by showing its association with iron-deficiency anemia requiring transfusions, and scleroderma renal crisis. There are, however, no data on the effect of HSCT on GAVE.

Three patients (all women, median age $36 \mathrm{yrs}$ ) had persistent bleeding from GAVE in the 12-24 months prior to autologous HSCT at our institution. The diagnosis of GAVE was made by endoscopic assessment. All patients required regular transfusions and multiple endoscopic treatments with argon plasma coagulation (APC). They had significant skin and pulmonary involvement refractory to multiple disease-modifying agents including CYC. Patients 1 and 2 had each received a total of $3.75 \mathrm{~g} / \mathrm{m}^{2}$ in divided doses. Patient 3 had received a total of $2 \mathrm{~g} / \mathrm{m}^{2}$. This pre-HSCT CYC therapy did not alter the natural history of GAVE, with all patients remaining transfusion-dependent.

The red cell transfusion requirements in the period of 12-24 months pre-HSCT were 91, 24, and 14 units for patients 1, 2, and 3, respectively.
After informed written consent, as part of a phase II trial in our institution, stem cells were mobilized with CYC $\left(2 \mathrm{~g} / \mathrm{m}^{2}\right)$. Unmanipulated autologous stem cells were infused following CYC $(200 \mathrm{mg} / \mathrm{kg})$ and antithymocyte globulin $(40 \mathrm{mg} / \mathrm{kg}$ ) conditioning. The transplant protocol did not involve any graft manipulation because there is little evidence for any clinical benefit of this from the current literature of autologous HSCT for autoimmune diseases ${ }^{7}$. This approach is also supported by the EBMT guidelines ${ }^{4}$

The combined median pretransfusion hemoglobin for our patients prior to HSCT was $76 \mathrm{~g} / 1$ (range $47-88 \mathrm{~g} / 1)$. This improved to $121 \mathrm{~g} / \mathrm{l}$ post-HSCT (range 91-142 g/l, p < 0.0001; Figure 1). All patients achieved transfusion independence by Day 20 post-HSCT and maintained stable hemoglobin at median followup of 420 days. Surveillance endoscopy performed in 1 of the patients showed significant improvement in vascular ectasia, which had been detected prior to HSCT (Figure 2). SSc disease activity scores and functional status, including the Rodnan skin and the Health Assessment Questionnaire scores, also improved following transplant.

GAVE is associated with early diffuse cutaneous SSc and morbidity because of severe anemia ${ }^{8}$. Current treatment for GAVE is repeated endoscopic coagulation, usually with APC. This does not address the underlying pathophysiology and requires multiple endoscopic procedures. The effect of autologous HSCT on GAVE is unknown. One case series reported resolution of GAVE post-intravenous CYC, suggesting a role for the immunomodulatory effect of this agent on the underlying pathophysiology of GAVE ${ }^{9}$. However, those patients became transfusion-independent much later, at 6-8 months post-CYC. This may reflect the higher concentrated dose of CYC in HSCT that resulted in significant improvement in skin scores and function, raising the possibility that high-dose immunosuppression is required to reverse both the systemic skin fibrosis and gastric vascular dysfunction. Similarly, in our patient cohort, there was no major benefit from pulsed CYC, suggesting a different mechanism of action of HSCT.

Our case series suggests that autologous HSCT may be an effective disease-modifying therapy for GAVE as a complication of SSc. Prospective studies of autologous HSCT for SSc should analyze the endoscopic features of GAVE in response to HSCT, and correlate these with immunological and clinical variables to fully ascertain this welcome and unexpected benefit of HSCT in these patients.

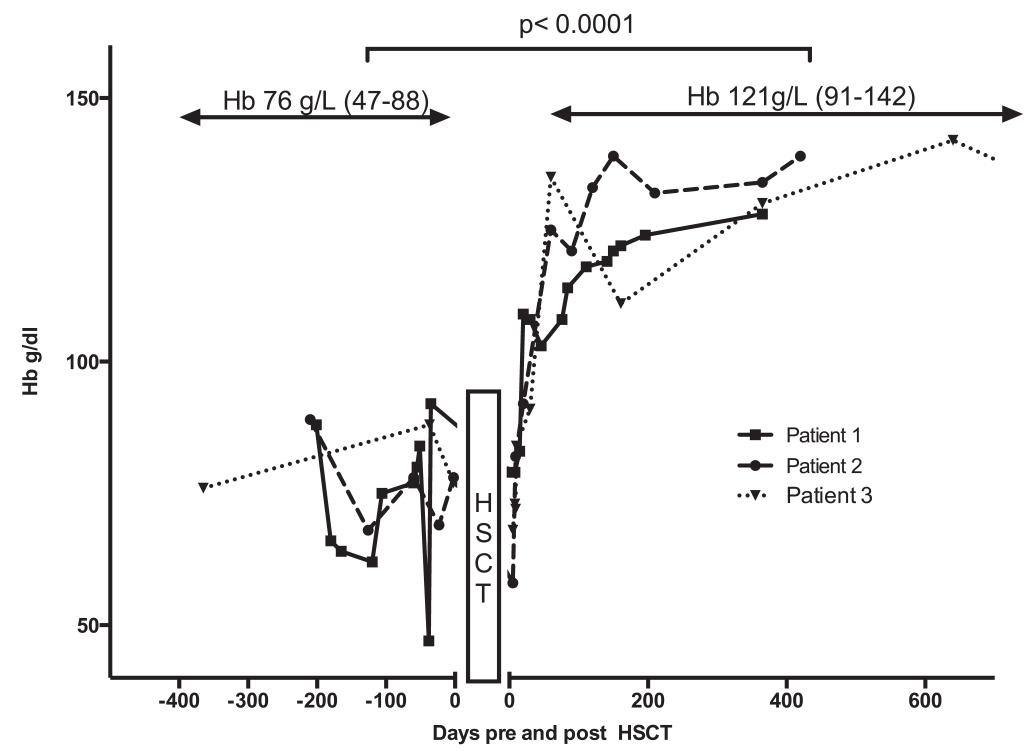

Figure 1. Hemoglobin before and after autologous HSCT. HSCT: hematopoietic stem cell transplantation. 

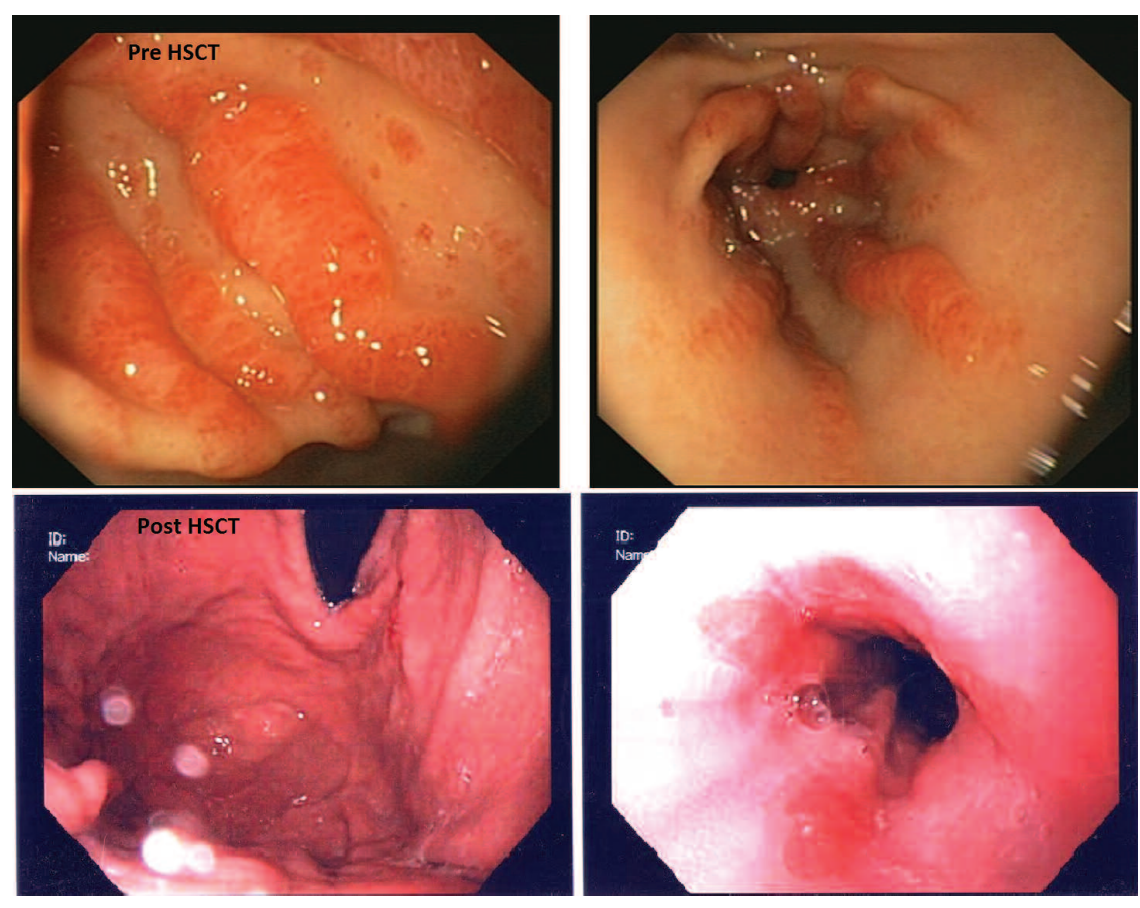

Figure 2. Endoscopic images before and after autologous HSCT. HSCT: hematopoietic stem cell transplantation.

ABIR BHATTACHARYYA, MBBS, FRACP, FRCPA, Department of Haematology, St. Vincent's Hospital, Sydney; JOANNE SAHHAR, MBBS, FRACP, Department of Rheumatology, Monash Health and Centre for Inflammatory Diseases, Monash University, Clayton; SAM MILLIKEN, MBBS, FRACP, FRCPA; DAVID MA, MBBS, DM, FRACP, FRCPA, Department of Haematology, St. Vincent's Hospital, Sydney; HELEN ENGLERT, MS, BS, Dip, Epid, MSc (Epid), PhD, FRACP, FAFPHM, Department of Rheumatology, Westmead Hospital, Westmead; KATHLEEN TYMMS, MBBS, FRACP, Canberra Rheumatology, Canberra; MARK DANTA, B Med, MD, DTM\&H, MPH, FRACP, Department of Gastroenterology; JOHN MOORE, MBBS, MD, FRACP, FRCPA, Department of Haematology, St. Vincent's Hospital, Sydney, Australia. Address correspondence to Dr. A. Bhattacharyya, St. Vincent's Hospital, Haematology, 390 Victoria St., Sydney, New South Wales 2010, Australia.E-mail: abir123@gmail.com

\section{REFERENCES}

1. Hissaria P, Lester S, Hakendorf P, Woodman R, Patterson K, Hill $\mathrm{C}$, et al. Survival in scleroderma: results from the population-based South Australian Register. Intern Med J 2011;41:381-90.

2. Burt RK, Shah SJ, Dill K, Grant T, Gheorghiade M, Schroeder J, et al. Autologous non-myeloablative haemopoietic stem-cell transplantation compared with pulse cyclophosphamide once per month for systemic sclerosis (ASSIST): an open-label, randomised phase 2 trial. Lancet 2011;378:498-506.

3. van Laar JM, Farge D, Sont JK, Naraghi K, Marjanovic Z, Larghero J, et al. Autologous hematopoietic stem cell transplantation vs intravenous pulse cyclophosphamide in diffuse cutaneous systemic sclerosis: a randomized clinical trial. JAMA 2014;311:2490-8.

4. Snowden JA, Saccardi R, Allez M, Ardizzone S, Arnold R, Cervera $\mathrm{R}$, et al. Haematopoietic SCT in severe autoimmune diseases: updated guidelines of the European Group for Blood and Marrow Transplantation. Bone Marrow Transpl 2012;47:770-90.

5. Gyger G, Baron M. Gastrointestinal manifestations of scleroderma: recent progress in evaluation, pathogenesis, and management. Curr Rheumatol Rep 2012;14:22-9.

6. Ghrénassia E, Avouac J, Khanna D, Derk CT, Distler O, Suliman YA, et al. Prevalence, correlates and outcomes of gastric antral vascular ectasia in systemic sclerosis: a EUSTAR case-control study. J Rheumatol 2014;41:99-105.

7. Moore J, Brooks P, Milliken S, Biggs J, Ma D, Handel M, et al. A pilot randomized trial comparing CD34-selected versus unmanipulated hemopoietic stem cell transplantation for severe, refractory rheumatoid arthritis. Arthritis Rheum 2002;46:2301-9.

8. Ingraham KM, O’Brien MS, Shenin M, Derk CT, Steen VD. Gastric antral vascular ectasia in systemic sclerosis: demographics and disease predictors. J Rheumatol 2010;37:603-7.

9. Schulz SW, O’Brien M, Maqsood M, Sandorfi N, Del Galdo F, Jimenez SA. Improvement of severe systemic sclerosis-associated gastric antral vascular ectasia following immunosuppressive treatment with intravenous cyclophosphamide. J Rheumatol 2009;36:1653-6.

J Rheumatol 2015;42:3; doi:10.3899/jrheum.141234 